Erratum

\title{
Erratum to "Incidence and Spatial Distribution of Caribbean Yellow Band Disease in La Parguera, Puerto Rico"
}

\author{
Francisco J. Soto-Santiago ${ }^{1,2}$ and Ernesto Weil ${ }^{1}$ \\ ${ }^{1}$ Department of Marine Sciences, University of Puerto Rico, Mayagüez, P.O. Box 9000, San Juan, PR 00681, USA \\ ${ }^{2}$ Department of Environmental Sciences, University of Puerto Rico, Río Piedras Campus, P.O. Box 70377, \\ San Juan, PR 00936, USA
}

Correspondence should be addressed to Francisco J. Soto-Santiago; franciscoj_soto@yahoo.com

Received 2 October 2013; Accepted 10 October 2013

Copyright (C) 2013 F. J. Soto-Santiago and E. Weil. This is an open access article distributed under the Creative Commons Attribution License, which permits unrestricted use, distribution, and reproduction in any medium, provided the original work is properly cited.

In the article, Table 4 is the same as Table 3. This is an error. The captions of each table are correct but the tables are the same. Below is the correct Table 4 with its proper caption. 
TABLE 4: Colony distribution departure from randomness; $z$ and $P$ values (in parenthesis) from the test of significance for the three $100 \mathrm{~m}^{2}$ quadrants in the different sites. (-): no data was found. $(*)$ : not significant data.

\begin{tabular}{|c|c|c|c|c|c|c|}
\hline \multirow{2}{*}{ Reef } & \multicolumn{2}{|c|}{ Q 1 } & \multicolumn{2}{|c|}{ Q2 } & \multicolumn{2}{|c|}{ Q 3} \\
\hline & Healthy + YBD & YBD & Healthy + YBD & YBD & Healthy + YBD & YBD \\
\hline Pelotas & $-3.84(P=.000)$ & $4.72(P=.011)$ & - & - & - & - \\
\hline Enrique & $*$ & * & $-3.47(P=.000)$ & $-4.03(P=.000)$ & $-2.23(P=.000)$ & $-1.4(P=.000)$ \\
\hline M. Luna & $-7.5(P=.000)$ & $-2.45(P=.000)$ & $-10.9(P=.000)$ & $-2.29(P=.000)$ & $-12.5(P=.000)$ & $-4(P=.000)$ \\
\hline Turrumote & $-5(P=.000)$ & $-1.65(P=.000)$ & $-5.2(P=.000)$ & $-2.1(P=.001)$ & $-4.12(P=.000)$ & $*$ \\
\hline Buoy & $-2.27(P=.000)$ & * & $-1.13(P=.003)$ & * & $-2.85(P=.000)$ & $-0.25(P=.005)$ \\
\hline Weinberg & $-0.7(P=.038)$ & $-0.4(P=.000)$ & $-2.83(P=.000)$ & $0.08(P=.011)$ & $4.51(P=.000)$ & $-2.42(P=.005)$ \\
\hline
\end{tabular}



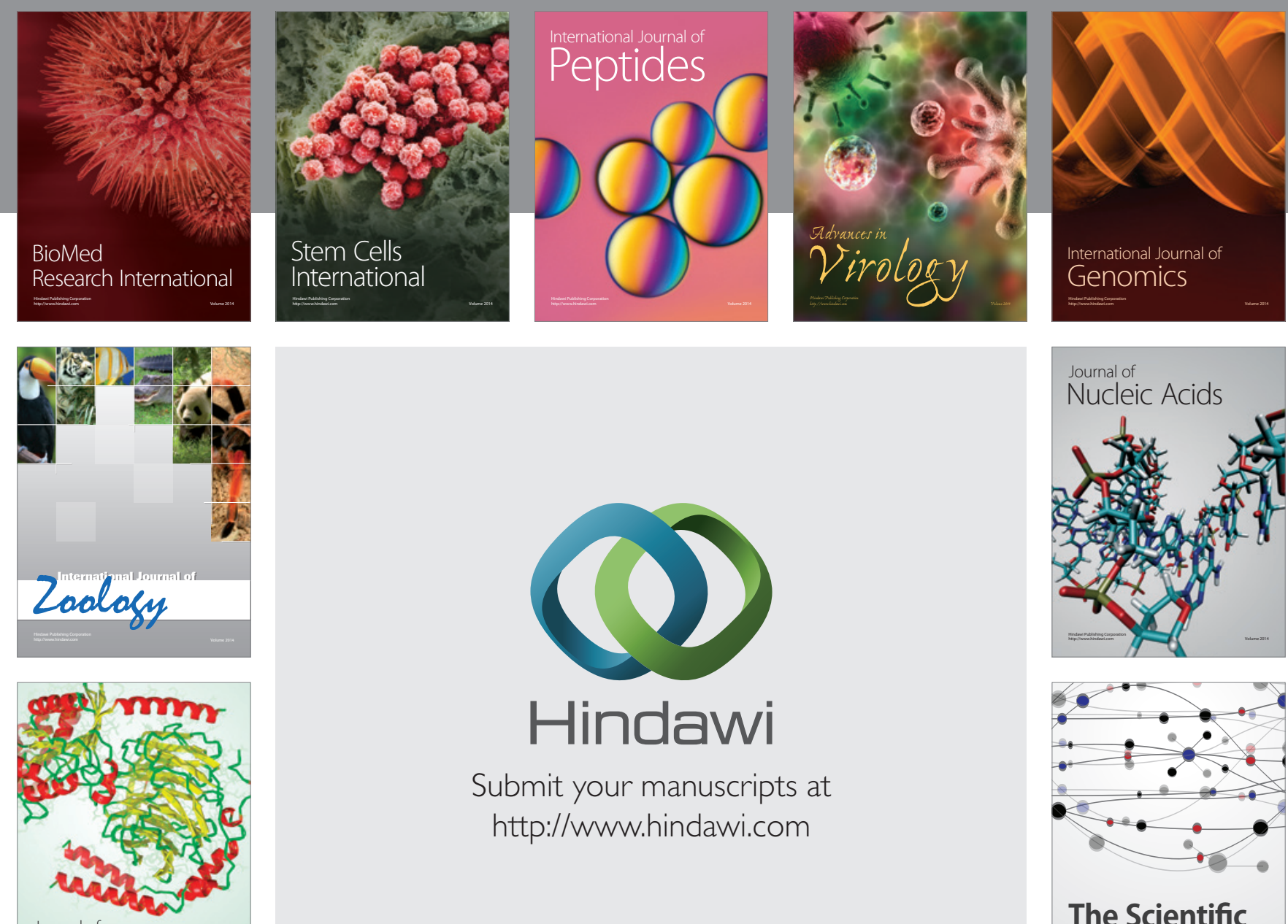

Submit your manuscripts at

http://www.hindawi.com

Journal of
Signal Transduction
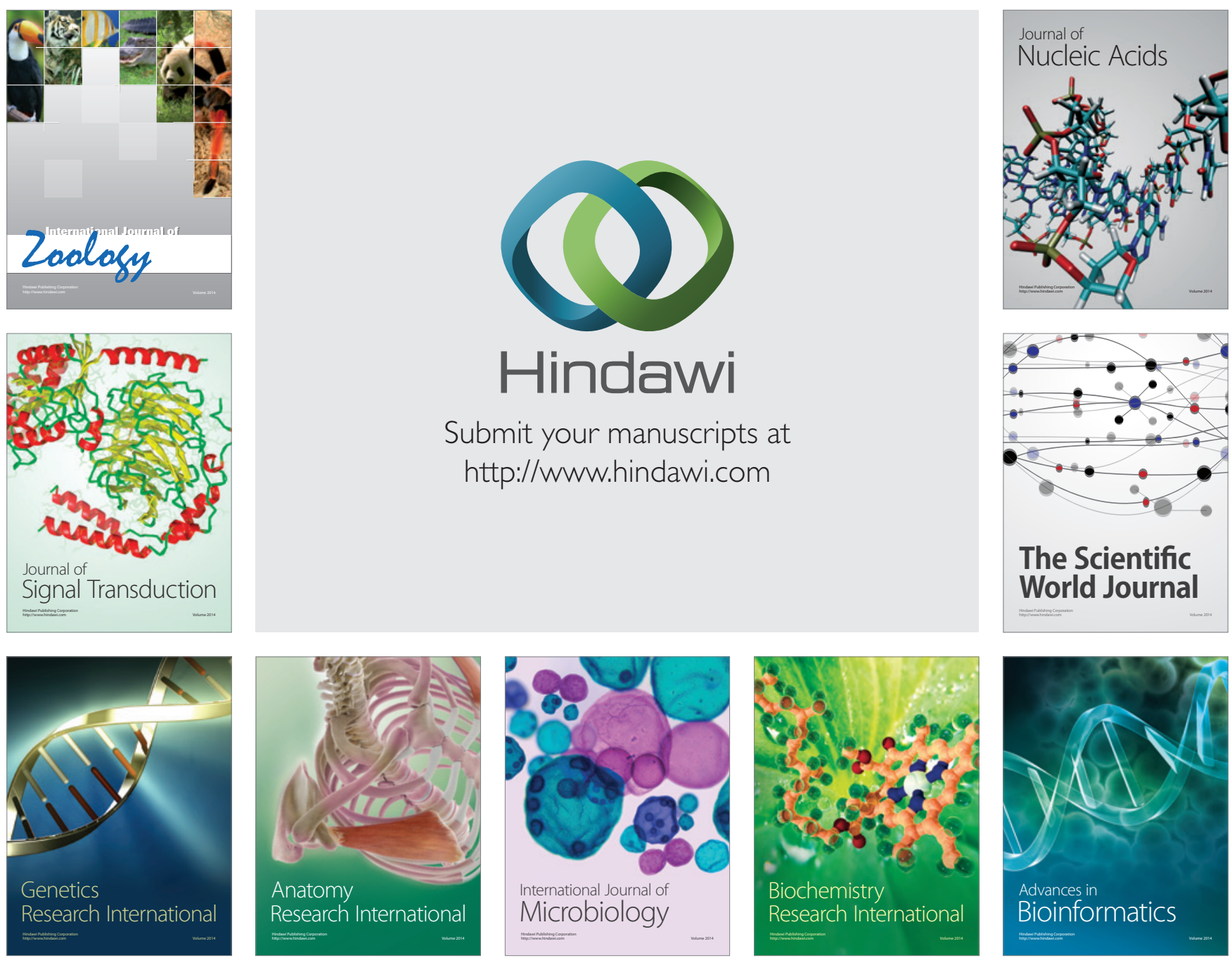

The Scientific World Journal
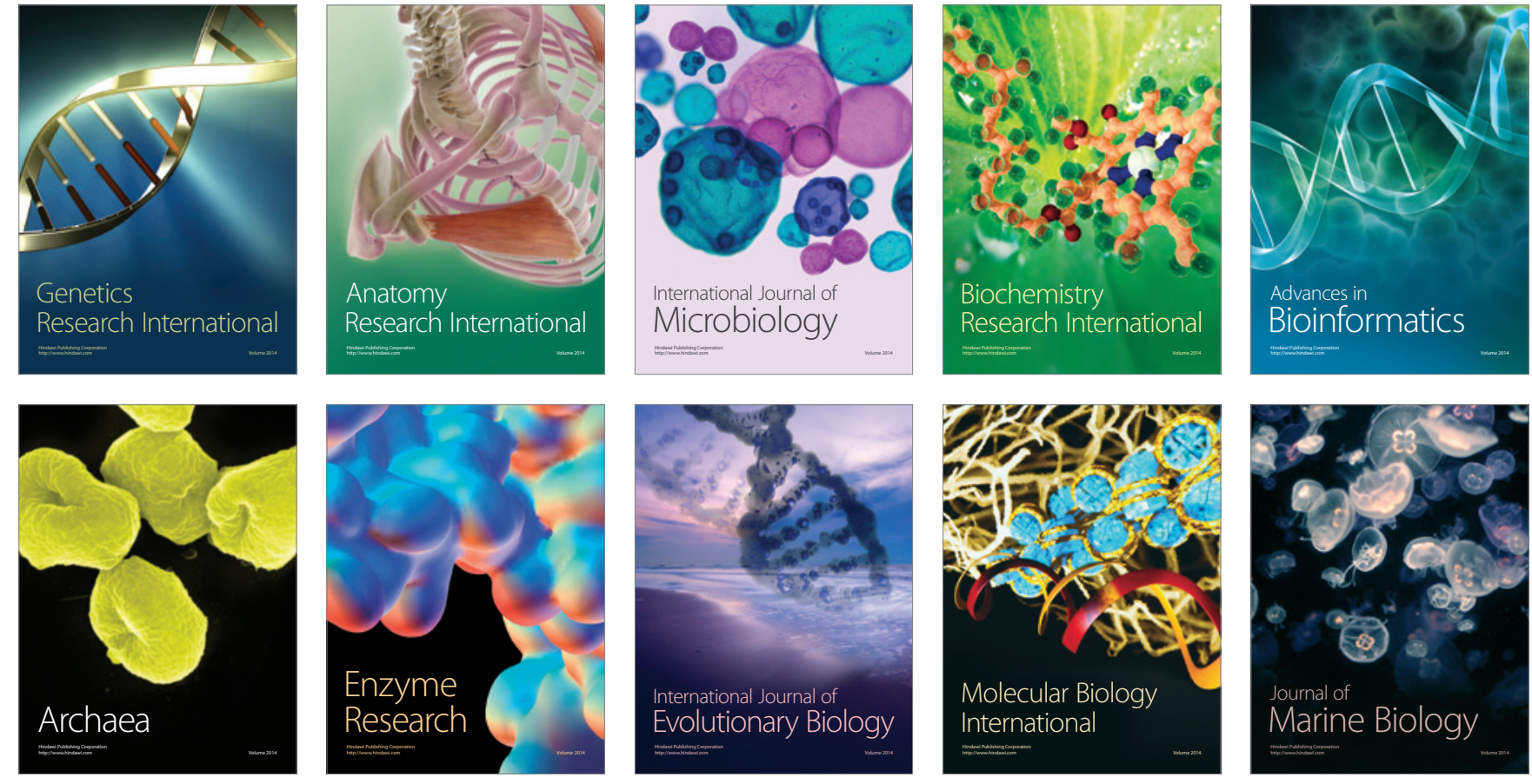